\title{
Análise da microbiota bacteriana colonizadora de lesões provocadas por queimaduras nas primeiras $\mathbf{2 4}$ horas
} Bacterial microbiota colonization analysis of burn wounds in the initial 24 hours

Hamilton Aleardo Gonella ${ }^{1}$, Francine Eloisa Eamanach ${ }^{1}$ Julia Cristina de Souza ${ }^{1}$, Maria Elisa Zuliani Maluf ${ }^{1}$

\begin{abstract}
RESUMO
Introdução: A ferida da queimadura, a princípio, é estéril. Esse período varia de 24 a 72 horas. Pela análise microbiológica, o Staphylococcus aureus é o germe mais frequentemente encontrado, seguido de Pseudomonas aeruginosa e Escherichia coli. Objetivo: Analisar qualitativamente a microbiota colonizadora das lesões por queimaduras, nas primeiras 24 horas do ocorrido, em 25 pacientes atendidos no Centro de Tratamento de Queimados (CTQ) do Conjunto Hospitalar de Sorocaba(CHS). Método: Foram estudadas as amostras da margem e da área central da ferida pela técnica de coleta com uso de swab estéril. Resultados: Das 50 amostras analisadas, 15 (60\%) pacientes possuíam positividade para colonização de microrganismos tanto na região central quanto na margem destas. Nas amostras obtidas da região central da lesão, pudemos encontrar seis colonizadas pelo microrganismo Staphylococcus sp e oito por Staphylococcus aureus, com valores semelhantes às amostras retiradas da região marginal, com oito colonizadas pelo Staphylococcus sp e sete pelo Staphylococcus aureus. Conclusão: As lesões por queimaduras nas primeiras 24 horas são colonizadas por microrganismos. A microbiota possui correlação com o descrito na literatura consultada. A análise microbiológica precoce de queimaduras demonstra-se pertinente para a constatação de colonização e subsequente manejo para prevenção de invasão e de infecção dessas lesões, dessa forma contribuindo indiretamente para a queda na morbidade e mortalidade associada às queimaduras.

Palavras-chave: queimaduras; ferimentos e lesões; infecção dos ferimentos; técnicas de cultura; técnicas microbiológicas.

ABSTRACT

Introduction: The burns wound initially is sterile, if no contaminated materials are put on the burn area or if the patient have not fell on dirty surfaces. This time gap, from 24 to 72 hours, is considered clean or sterile. Staphylococcus aureus is the most frequently found germ on burn wounds, followed by Pseudomonas aeruginosa and Escherichia coli. Objective: Quantitative analysis of the microbiota of the burn wounds, in the initial 24 hours of the injurie, in 25 patients from the Burns Unit of "Conjunto Hospitalar de Sorocaba". Methods: Samples taken with swab technic from the center and periphery of the wounds were analyzed. Results: In an amount of 50, 15 samples (60\%) of the patients were tagged positive with peripheric and central colonization of microorganisms. In the sample's central portion, 6 were colonized by Staphylococcus sp and 8 by Staphylococcus aureus. Conclusion: The burn wounds in the initial 24 hours are colonized with microorganisms. The main microbiota is similar to the previously consulted literature. With this conclusion, the early microbiological analysis seems pertinent to the confirmation of wound colonization and the following care to prevent its infection, contributing indirectly to the decrease of morbidity and mortality related to burning.

Keywords: burns; wounds and injuries; wound infection; culture techniques; microbiological techniques.
\end{abstract}

${ }^{1}$ Pontifícia Universidade Católica de São Paulo (PUC-SP), Faculdade de Ciências Médicas e da Saúde - Sorocaba (SP), Brasil. Contato: hagonella@hotmail.com

Recebido em 27/06/2015. Aceito para publicação em 10/11/2015. 


\section{INTRODUÇÃO}

Segundo a Sociedade Brasileira de Queimaduras (SBQ), no Brasil acontecem um milhão de casos de queimaduras a cada ano, sendo que 200 mil são atendidos em serviços de emergência e 40 mil demandam hospitalização.

As queimaduras estão entre as principais causas externas de morte registradas no país, perdendo apenas para outras causas violentas, que incluem acidentes de transporte e homicídios. ${ }^{1}$ Sua alta taxa de mortalidade deve-se principalmente à infecção da ferida, que pode evoluir com septicemia devido à exposição de vasos e à invasão de microrganismos na circulação sistêmica, corroborando para possíveis complicações renais, adrenais, cardiovasculares, pulmonares, musculoesqueléticas, hematológicas e gastrointestinais. ${ }^{2}$

As queimaduras são um ambiente propício para o desenvolvimento das infecções, em decorrência de atingir a pele, primeiro órgão na defesa da "entrada de germes" e sua função imunológica.

Os fatores de risco associados à infecção são próprios do paciente. Como exemplos são citados a extensão e profundidade da queimadura, a idade, as doenças preexistentes, a desnutrição, a temperatura e a umidade da lesão, a ocorrência de choque e a acidose decorrente do mecanismo fisiopatológico de lesões graves. Esses podem, ainda, estar relacionados ao microrganismo, como número, virulência, mobilidade, resistência bacteriana e produtos extracelulares, como enzimas ou exotoxinas. ${ }^{3}$

Os microrganismos podem ser originários de locais diversos, como do próprio acidente ou até mesmo da pele íntegra ao redor das lesões. Podem, ainda, advir de forma endógena, da orofaringe e do reto. Também é possível que sejam provenientes de procedimentos terapêuticos invasivos, de translocações bacterianas, de focos à distância e exógenos, a partir da equipe e das visitas, situação esta em que temos as infecções cruzadas, muitas de origem do ambiente hospitalar.,

Diante dessas estatísticas, torna-se necessário um monitoramento contínuo da microbiota da escara do queimado. Por meio de exames diagnósticos, é possível um tratamento mais precoce e adequado das infecções - complicação mais frequente da queimadura - e, assim, uma menor taxa de morbidade da área afetada pela queimadura. ${ }^{6}$

Russo, ${ }^{7}$ referindo-se ao papel da infecção, relata: os pesquisadores Lustgarden (1891), Stocis (1903) já relacionavam que, nas fases iniciais das queimaduras, a infecção fosse responsável por parte dos sintomas tóxicos. Aldrich (1933) verificou que, nas primeiras 12 horas, as áreas eram praticamente estéreis. Cruisckshank (1935) falava que a positividade das culturas era maior a partir do segundo dia. Colebrook, Ducan e Butterfield (1947) acrescentam a importância do ambiente, do material e do pessoal de serviço.

Teplitz ${ }^{8}$ refere a eficácia da terapêutica antibacteriana tópica para a prevenção da colonização bacteriana dentro de 48 horas.

A ferida da queimadura, a princípio, é estéril, se não foram colocados materiais contaminados sobre a área queimada ou se o paciente não tiver caído sobre superfícies sujas. Esse período, considerado estéril, varia de 24 a 72 horas. ${ }^{4}$ Porém o tecido necrótico resultante é rapidamente colonizado por bactérias endógenas e exógenas, produtoras de proteases, que levam à liquefação e à separação da escara, tornando-a um tecido de granulação responsável pela cicatrização da lesão. ${ }^{3,9}$

As taxas de morbidade e mortalidade em queimados possuem como causa principal a infecção de pele. Essa situação pode ser definida, quantitativamente, por um valor maior ou igual a $10^{5}$ unidades formadoras de colônias por grama de tecido (UFC/g). A área queimada destrói os tecidos e células responsáveis pela barreira de defesa contra patógenos externos, sendo que a imunodeficiência resultante permite a rápida proliferação bacteriana. Em um dia completo ela pode aumentar exponencialmente. . $^{8,10}$

Assim, é importante realizar uma sequência de análises da microbiota dos pacientes queimados, desde sua chegada e durante sua internação, para um conhecimento efetivo da colonização bacteriana até o estabelecimento de uma infecção, a fim de estabelecer mecanismos necessários para coibir as infecções nos pacientes queimados, que correspondem a $75 \%$ dos óbitos.

Para a análise qualitativa dessas bactérias, dois recursos são amplamente utilizados: a técnica com coleta por uso de swab e, mais especificamente, a biópsia de pele. A técnica por uso de swab possui sensibilidade de $100 \%$, mostrando-se útil na exclusão de infecção onde o resultado é negativo. Entretanto, com especificidade de $77,4 \%$, há a possibilidade de mais de $20 \%$ de falsos-positivos. Por intermédio da análise microbiológica realizada com a técnica swab, o Staphylococcus aureus é o germe mais frequentemente encontrado nas lesões por queimadura, seguido de Pseudomonas aeruginosa e Escherichia coli.,6

Assim, prevenir ou tratar as infecções da área lesada é um dos fatores de grande importância no desenvolvimento do quadro clínico geral do paciente queimado.

A grande maioria dos autores, entre eles Russo: ${ }^{7}$ Aldrich (até 12 horas) e Cruisckshank (48 horas), fala na ausência de colônias na área lesada. Citaremos mais alguns: Monafo e Ayvazian, ${ }^{11}$ Artz, Moncrief e Pruitt ${ }^{12}$ e Gomes. ${ }^{13}$

Entretanto, Erol et al. ${ }^{14}$ apresentam um estudo para pesquisar as microbiotas bacterianas existentes em vários períodos da internação e, assim, mostram que, no início da lesão térmica, não ocorria microbiota em 35,3\% dos casos.

\section{OBJETIVO}

Analisar qualitativamente a microbiota colonizadora das lesões provocadas por queimaduras em 25 pacientes, nas primeiras 24 horas do ocorrido, em pacientes ambulatoriais do Centro de Tratamento de Queimados (CTQ) do Conjunto Hospitalar de Sorocaba (CHS).

\section{MATERIAIS E MÉTODOS}

Foram analisadas amostras de 25 pacientes admitidos no CTQ, sendo 13 pacientes do sexo masculino (52\%) e 12 do feminino (48\%), com uma média de idade de 22 anos e tempo médio, entre a ocorrência da lesão e a coleta, de aproximadamente 14 horas.

Foi aplicado o termo de consentimento livre esclarecido e questionário a esses pacientes.

Foi coletada uma amostra da margem e uma da área central da ferida pela técnica de coleta com uso de swab es- 
téril. Em seguida, o material armazenado em caldo Brain Heart Infusion (BHI) foi imediatamente enviado ao Laboratório de Microbiologia da Faculdade de Ciências Médicas e da Saúde da Pontifícia Universidade Católica de São Paulo (FCMS-PUC-SP), onde foi processado o isolamento e feita a identificação dos eventuais microrganismos. Após a coleta e o transporte, a amostra colhida foi suspensa em volume pequeno de caldo TSB (Tryptic Soy Broth), deixando-a homogênea, e assim utilizada para inocular em Ágar Sangue MacConkey e fazer uma lâmina para coloração de Gram.

$\mathrm{O}$ isolamento foi feito utilizando-se meios de cultura específicos para Gram-positivas (Placa de Ágar Sangue) e Gram-negativas (Ágar MacConkey) e as amostras foram semeadas em meio de tioglicolato para verificar a eventual presença de anaeróbios.

Realizada a avaliação da cultura, a identificação foi feita após a coloração pelo método de Gram dos diferentes tipos de colônias encontradas utilizando-se as séries bioquímicas tradicionais. ${ }^{10}$

\section{Análise estatística}

Para a análise dos resultados, foram aplicados os seguintes testes: ${ }^{15}$

1. teste do $\chi^{2}$ com o objetivo de comparar as presenças dos patógenos Staphylococcus sp e Staphylococcus aureus nas regiões centro, margem e centro e margem simultaneamente;

2. teste Kappa de concordância com o objetivo de estudar as regiões centro e margem, em relação às presenças dos microrganismos estudados;

3. teste de Mann-Whitney com o objetivo de analisar duas amostras independentes.

\section{RESULTADOS}

Todos os pacientes tiveram queimaduras de segundo grau, exceto o paciente XIV, que também apresentou lesões de terceiro grau. Pudemos observar diferentes partes do corpo acometidas, sendo mais frequentes as mãos, 11 casos (44\%), e a face, 7 casos $(28 \%)$.
O agente físico foi o responsável por 22 queimaduras (88\%), sendo 11 (44\%) do tipo escaldo, 6 (24\%) por chama de fogo, $4(16 \%)$ por contato, 1 (4\%) por vapor d'água; enquanto o agente químico foi o causador de duas queimaduras e a eletricidade ("flash burn") de apenas uma. As queimaduras em ambiente domiciliar ocorreram em 19 pacientes (76\%), enquanto 6 pacientes (24\%) foram vítimas de acidente ocupacional.

Dez pacientes fizeram uso prévio, à coleta da amostra, de substâncias tópicas nas lesões, tais como sulfato de neomicina + bacitracina, sulfacetamida sódica associada à trolamina, Hipoglós ${ }^{\circledR}$, loção oleosa dersani ${ }^{\circledR}$ e colagenase, e um paciente fez uso prévio de dois comprimidos de cefalexina oral.

Por meio da análise microbiológica em cultura específica para Gram-positivas e Gram-negativas (Quadro 1), foram isolados patógenos em 16 amostras. Dentre esses, foram encontrados os microrganismos Staphylococcus sp, Staphylococcus aureus, Bacillus sp, Escherichia coli e Citrobacter diversus.

Ademais, dos 25 pacientes estudados, 16 (64\%) tiveram em suas lesões a presença de bactérias; além disso, dos 15 pacientes que não receberam nenhum tipo tratamento tópico ou oral, $10(66,67 \%)$ tiveram a presença de bactérias em ambos os locais estudados.

Das 50 amostras analisadas no laboratório de microbiologia, 15 (60\%) pacientes possuíam positividade para colonização de microrganismos tanto na região central quanto na margem destas, enquanto 9 (38\%) não apresentaram amostras com patógenos. Apenas um paciente ( $2 \%$ ) obteve amostra positiva unicamente no centro da lesão (Tabela 1).

Tabela 1. Análise da concordância da colonização dos microrganismos nas regiões das lesões por teste Kappa.

\begin{tabular}{lcccc} 
Centro & + & Margem & - & Total \\
+ & 15 & & 1 & 16 \\
- & 0 & & 9 & 9 \\
Total & 15 & & 10 & 25 \\
\hline
\end{tabular}

$\mathrm{Kw}=0,92 ; \mathrm{Z}$ calculado=4,53 ( $\mathrm{p}<0,0001)$.

Quadro 1. Resultados das amostras sob análise do setor de microbiologia.

\begin{tabular}{|lcc|}
\hline Pacientes & Margem & Centro \\
\hline I, II, III, IX, X, XI, XVI, XX, XXII & Negativo & Negativo \\
\hline IV, V, XVIII & Staphylococcus sp & Staphylococcus sp \\
\hline VI & Staphylococcus aureus & Escherichia coli e Citrobacter diversus \\
\hline VII & Staphylococcus aureus & Staphylococcus sp \\
\hline VIII & Staphylococcus aureus & Bacillus sp \\
XII, XIII, XXIV, XXV & Staphylococcus sp & Staphylococcus aureus \\
\hline XIV, XVII, XXIII & Staphylococcus aureus & Staphylococcus aureus \\
XV & Staphylococcus $\mathrm{sp}$ & Staphylococcus aureus \\
XIX & Negativo & Staphylococcus aureus \\
XXI & Staphylococcus aureus & Staphylococcus sp \\
\hline
\end{tabular}


Das 25 amostras obtidas da região central da lesão, pudemos encontrar 6 colonizadas pelo microrganismo Staphylococcus sp e 8 por Staphylococcus aureus, com valores semelhantes às 25 amostras retiradas da região marginal, com 8 colonizadas pelo Staphylococcus sp e 7 pelo Staphylococcus aureus. Tanto o Staphylococcus aureus quanto o Staphylococcus sp colonizaram simultaneamente três amostras, cada um em ambas as regiões (Tabela 2). Apenas uma amostra coletada apresentou dois tipos de bactérias, Escherichia coli e Citrobacter diversus, e outra apresentou Bacillus sp, dados não representados na tabela.

\section{DISCUSSÃO}

Segundo pesquisa de Russo, ${ }^{7}$ a área queimada era isenta de bactérias ou seu aumento era gradativo entre 12 e 48 horas, pelos dados dos autores Aldrich (1933) e Cruisckshank (1935). Colebrook, Ducan e Butterfield (1947) acrescentam a importância do ambiente, do material e do pessoal de serviço, sugerindo as infecções hospitalares. Para Sucena, a lesão é considerada estéril por um período de 24 a 72 horas, uma vez assegurado que a queimadura não foi manipulada ou contaminada por substâncias tópicas e/ou outros materiais oriundos do local do acidente. ${ }^{4}$

A origem da flora bacteriana é diversa, podendo ser proveniente de más condições de higiene com consequente colonização por microrganismo de região genital, intestinal e orofaringe. A contaminação pode ser agravada por diversos fatores, como a existência de doenças prévias, desnutrição, patologias psiquiátricas, como depressão e tentativa de suicídio, e a utilização frequente de antibióticos, determinando a seleção de microrganismos multirresistentes. ${ }^{12}$

O estudo do HPS-Porto Alegre com pacientes queimados demonstrou, por meio da coleta com o swab, que os germes mais frequentemente encontrados foram o Staphylococcus aureus, seguido de Pseudomonas aeruginosa e Escherichia coli. ${ }^{3}$

A grande maioria dos autores ${ }^{4,711-13}$ refere não haver flora bacteriana entre as primeiras horas da queimadura (24 a 48 horas). Porém, seguindo a medicina baseada em evidências, o único trabalho por nós encontrado foi o de Erol et al., ${ }^{14}$ que referem não existir microbiota em 35,3\%, embora não se referindo ao tempo dessa ocorrência, uma vez que estavam avaliando a existência da mudança da flora bacteriana ao passar do tempo de internação, sendo parecido com o resultado deste trabalho.

Dentre os resultados obtidos pelo nosso estudo, verificamos que dos 25 pacientes analisados, 16 (64\%) apresentaram resultados positivos para germes, e nos pacientes que não sofreram manipulação das lesões, representados por 15, 10 $(66,67 \%)$ apresentaram colonização (Tabela 3).

Os microrganismos mais frequentemente encontrados na pesquisa tiveram correlação com a literatura em relação à Gram-positiva Staphylococcus aureus, sendo que das 31 amostras colonizadas, 15 apresentaram esse patógeno. A Gram-positiva Staphylococcus sp foi detectada em 14 amostras dessa totalidade. Foram isoladas duas enterobactérias, Escherichia coli e Citrobacter diversus, em um mesmo paciente, que sofreu queimadura química por cimento e não utilizou nenhuma medicação no local. No paciente VIII, observamos a presença do germe Bacillus sp somente no centro da lesão.

Percebemos excelente concordância $(\mathrm{Kw}=0,92)$ entre as frequências de microrganismos na margem e no centro das lesões (Tabela 3), revelando, assim, uma tendência de colonização simultânea nas regiões, independentemente do germe colonizador.

Os dados levantados constataram que as lesões provocadas por queimaduras nas primeiras 24 horas são colonizadas por microrganismos. Outrossim, a microbiota bacteriana predominante possui correlação com o descrito na literatura consultada.

Em vista dessas averiguações, a análise microbiológica precoce de queimaduras demonstra-se pertinente para a constatação de colonização e o subsequente manejo para prevenção de invasão e de infecção dessas lesões, dessa forma contribuindo indiretamente para a queda na morbidade $\mathrm{e}$ mortalidade associada às queimaduras.

\section{CONCLUSÕES}

A microbiota predominante possui correlação com o descrito na literatura consultada. Sendo que 64\% dos pacientes com manipulação e $66,7 \%$ dos pacientes (15) sem manipulação das lesões, apresentaram colonização por microrganismos.
Tabela 2. Presença dos microrganismos de acordo com as regiões centro, margem e ambas analisada por teste do $\chi^{2}$.

\begin{tabular}{lcccc} 
& \multicolumn{4}{c}{ Microrganismos } \\
\cline { 2 - 5 } Região & & $\mathbf{A}$ & \multicolumn{3}{c}{ B } \\
\cline { 2 - 5 } & $\mathbf{n}$ & $\mathbf{\%}$ & $\mathbf{n}$ & $\%$ \\
Só centro & 6 & 35,3 & 8 & 44,4 \\
Só centro & 8 & 47,1 & 7 & 38,9 \\
Ambos & 3 & 17,6 & 3 & 16,7 \\
Total & 17 & 100,00 & 18 & 100,00
\end{tabular}

A: Staphylococcus sp; B: Staphylococcus aureus; $\chi^{2}$ : 0,32 e p=0,8504. Fonte: Siegel e Castellan Junior ${ }^{15}$.
Tabela 3. Mann-Whitney: amostras independentes.

\begin{tabular}{lcc} 
Resultado & Amostra 1 & Amostra 2 \\
\hline Tamanho da amostra & 16 & 16 \\
\hline Soma dos postos (Ri) & 184,0 & 344 \\
\hline Mediana & 1,00 & 2,00 \\
\hline $\mathrm{U}$ & 48,00 & \\
\hline $\mathrm{Z}(\mathrm{U})$ & 3,0151 & \\
\hline Valor p (unilateral) & 0,0013 & \\
\hline Valor p (bilateral) & 0,0026 & \\
\hline
\end{tabular}

Amostra 1: germes; Amostra 2: manipulação. 


\section{REFERÊNCIAS}

1. Vale ECS. Primeiro atendimento em queimaduras: a abordagem do dermatologista. An Bras Dermatol. 2005;80(1):9-19.

2. Barillo DJ, Paulsen SM. Management of burns to the hand. Wounds. 2003;15:4-9.

3. Gragnani A, Gonçalves ML, Feriani G, Ferreira IM. Análise microbiológica em queimaduras. Rev Soc Bras Cir Plást. 2005;20(4):237-40.

4. Sucena RC. Infecção cirúrgica. In: Sucena RC. Fisiopatologia e tratamento das queimaduras. São Paulo: Roca; 1982. p. 29-38.

5. Laitano FF, Arnt RA, Cosner AM, Doncatto LF. Estudo comparativo entre o exame de cultura da biópsia e o "swab" cutâneo para o diagnóstico de infecção em pacientes queimados do HPS- Porto Alegre. Rev Bras Cir Plást. 2008;23(3):162-6.

6. Bang RL, Gang RK, Sanyal SC, Mokaddas E, Ebrahim MK. Burn septicaemia: an analysis of 79 patients. Burns. 1998;24:354-61.

7. Russo AC. Fisiopatologia das queimaduras. In: Russo AC. Queimaduras. São Paulo: Livraria Luso-espanhola e Brasileira; 1958. p. 98-101.

8. Teplitz C. Patologia das queimaduras e fundamentos de suas infecções. In: Artz CP, Moncrief JA, Pruitt Jr BA.
Queimaduras. Rio de Janeiro: Interamericana; 1980. p. 41-84.

9. Sheridan R. Evaluation and management of the thermally injured patient. In: Freedberg IM, Eisen AZ, Wolff K, Austen KF, Goldsmith LA, Katz SI, editores. Fitzpatrick's dermatology in general medicine. 6th ed. New York: McGraw-Hill; 2003. p. 1220-9.

10. Oplustil CP, Zoccoli CM, Tobout NR, Sinto SI. Procedimentos básicos em microbiologia clínica. São Paulo: Sarvier; 2000. p. 63-64.

11. Monafo WW, Ayvazian VH. Terapeutica tópica. Clin Cir Am Norte. 1978;58(6):1157-71.

12. Artz CP, Moncrief JA, Pruitt Jr BA. Queimaduras. Rio de Janeiro: Interamericana; 1980.

13. Gomes DR. Infecção em queimados. In: Gomes DR, Serra MC, Pellon MA. Queimaduras. Rio de Janeiro: Revinter; 1995. p. 77-99.

14. Erol S, Altoparlak U, Akcay MN, Celebi F, Parlak M. Changes of microbial flora and wound colonization in burned patients. Burns. 2004;30(4):357-61.

15. Siegel SE, Castellan Junior NJ. Estatística não paramétrica para ciências do comportamento. $2^{\mathrm{a}}$ ed. Porto Alegre: Artmed; 2006. 